$\begin{gathered}\text { EPiC Series in Built Environment } \\ \text { Volume 2, 2021, Pages 587-596 } \\ \text { ASC 2021. 57th Annual Associated Schools } \\ \text { of Construction International Conference }\end{gathered}$
Built
Environment

\title{
Building Kits: Adapted Hands-on Building Activities for the Virtual Environment
}

\author{
Stacy A. Kolegraff \\ California Polytechnic State University \\ San Luis Obispo, CA
}

Due to the Coronavirus pandemic, traditional university classes, and any associated experiential hands-on learning laboratory, adapted to comply with safety standards for public health, transitioning from a traditional classroom environment to a virtual one. This paper discusses the creation of a hands-on building kit to continue experiential hands-on learning activities in the virtual environment, transitioning from the construction of a small wooden structure to a roughly two-foot square wall section. Each hands-on experiential exercise was completed after first introducing the material in a virtual class setting through recorded online lectures and readings. Pre- and post-surveys were conducted during each term to identify how students' confidence in building abilities, tool use, and quality control measures changed over the term, along with their confidence in identifying items for inspections. The results of the student surveys are presented and discussed, with additional analysis, providing insight into the types of learning activities that can be performed in a virtual environment, and the impact it has on student confidence as it pertains to building abilities and inspections. This information may assist construction management programs that are interested in developing hands-on experiential laboratory exercises in either the virtual or online environment.

Key Words: Experiential Learning; Curricula; Virtual Learning; Hands-On; Construction Management

\section{Introduction}

In the first quarter of 2020, the Coronavirus Disease (COVID-19) arrived in the United States and over 1300 universities and colleges cancelled in-person classes in the spring term. In fall, " $44 \%$ of institutions developed fully or primarily online instruction, $21 \%$ used a hybrid model and $27 \%$ offered fully or primarily in-person instruction" (Smalley, 2020). Construction management educators with experiential learning activities were tasked to either adapt their laboratory classes to a virtual environment or provide in-person exercises that met COVID-19 safety standards for public health. 
Since students perceive these hands-on building laboratories as effective and preferred ways on learning (Kline, Kolegraff, \& Kelting, 2020), adapted exercises were developed for students to complete the work virtually and independently. This paper presents adaptations made to the experiential learning laboratory exercises in a residential construction management course at a major university. A description of the hands-on building exercises and the alterations made for COVID response will be provided. Pre- and post-building surveys were distributed to the students, and the results of the survey will be presented and discussed for two quarters.

\section{Literature Review}

Lecture style courses are often utilized in higher educational institutions to deliver management theory (Pratt, 1998), and construction management education often delivers foundational subjects such as estimating, scheduling, and contracts utilizing a lecture style (Chinowsky et al., 2006). Since "the world does not always present problems that are topic specific and solved in a non-holistic manner" (Montoya et al., 2009, p. 66), some construction management curriculums have developed integrated laboratory style courses that incorporate estimating, scheduling, and contracts into one project-based course (Benhart et al., 2017). This course can be a capstone style course completed in a student's senior year, or as part of a curriculum that integrates these capstone classes across the curriculum giving students additional opportunities to solve complex problems (Benhart et al., 2017).

In conjunction with lecture content and in-class activities, some programs have developed experiential learning activities. These courses are meant to help students "connect the dots" between classroom theory and practical application. Kolegraff et al. (2019) studied integrated laboratory style courses to determine the types of instructional delivery methods students perceived to be effective and preferred. Of the 14 delivery methods surveyed, $57 \%$ of students ranked hands-on building as the most effective delivery method, with $59 \%$ of students surveyed stating it was their preferred delivery method.

These hands-on building laboratory activities not only help students 'connect the dots,' but also aid in both technical and soft skill development. A study by Kline et al. (2020) provided insight on how students perceived the impact of hands-on building in relation to their soft and technical skill development. Overall, student perceptions of both technical and soft skill development were positive, with $93 \%$ agreeing that the activities enhanced their technical skill development and $91 \%$ agreeing they enhanced soft skill development. Additionally, an overwhelming $97 \%$ considered the activities a valuable part of their construction management education.

Researchers have also seen success for hands-on experiential learning activities in a virtual environment. In a study that augmented hands-on laboratories with virtual laboratory environments, Kapici, Akcay, and Jong (2019) found that "when virtual laboratories are considered as an alternative for hands-on laboratories, they can be regarded as being as effective as hands-on laboratories" for the development of skills and conceptual knowledge.

Brinson (2015) reviewed 56 studies that compared learning outcome achievement in non-traditional laboratories (remote or virtual) and traditional, hands-on laboratories. The study found that "learning outcomes can be achieved at an equal or greater frequency with non-traditional laboratories, regardless of the outcome category being measured."

The studies by Kapici et al. (2019) and Brinson (2015) reviewed only scientific classes, however, and reviewed student learning based on the use of equipment. There is limited research, however, on 
hands-on building exercises in a virtual environment. This study describes hands-on building exercises that were implemented for remote instruction, and the impact the activities had on student confidence in both construction abilities and the identification of inspection items.

\section{Research Questions}

The following research questions were generated for this study:

1. How did students perceive hand-on experiential learning exercises impacted their confidence in building abilities?

2. How did students perceive hand-on experiential learning exercises impacted their confidence in identifying items required for inspection?

3. How did students perceive hands-on experiential exercises impacted their learning?

\section{Methodology}

A pre- and post-survey were developed to assess the change in students' learning and confidence in building activities and assemblies. The surveys were similar, with one distributed at the start of term before any building activities, and the other upon completion of all activities. These surveys were conducted in two separate construction management course sections, and the data was extracted for analysis.

For each course, students were assigned a student identification number so their survey results could be tracked and compared. A total of 18 questions were included in the first survey, which was distributed electronically to the students through the course learning management system (LMS). The survey included two different types of questions: confidence in building abilities and confidence in identifying items required for inspection. The questions included 5-point Likert scale responses, ranking their perception of the activities' impact on their overall confidence, in the following order:

1 - not even sure what you're talking about

2 - not at all confident

3 - slightly confident

4 - moderately confident

5 - highly confident

For the post-survey, additional questions were asked students to rank their learning and enjoyment of the activities, as well as any suggestions for the activities if the remote learning environment were to continue. These questions included a 10-point scale, ranking their perception of the activities' learning and enjoyment, with 1 being the lowest ranking and 10 being the highest ranking. Finally, students were asked to identify the activities they enjoyed the most and least throughout the term and provide any comments on the overall experience. 


\section{Course Format}

In a traditional, pre-COVID-19 environment, the quarter-long residential class met in-person for 13 hours each week for lecture, discussion, and individual and team assignments. For two weeks each quarter, students transitioned from the classroom to an in-person hands-on building project to apply and reinforce their knowledge learned from the previous weeks' assignments and discussions. During week four, students worked in teams to set anchor bolts and frame the floors, walls and roof of a small wood structure. During week seven, students completed the structure by applying house wrap, installing windows and a door, installing roofing materials, and completing exterior wood siding.

With the arrival of COVID-19, the course transitioned from in-person classes to virtual asynchronous instruction. The asynchronous format utilized exclusively recorded video content, reading assignments, activities and online asynchronous video discussions. All lecture content was delivered through the LMS via recorded video lectures, with optional times for students to meet synchronously online with the instructor to review content and ask questions. Utilizing recorded content developed by the instructor, as well as a curated list of online links and resources, the faculty strived to immerse the students in all aspects of residential construction, covering topics from land acquisition to building materials, and the warranty process. The course combined estimating, scheduling, residential methods, and contracts into one project-based integrated lab, where students worked towards the feasibility and analysis of all aspects of a new residential tract community. Relevant industry trends as well as means and methods were introduced so students received the necessary information to work towards the completion of their final project incrementally throughout the quarter. Each class was structured into weekly topic areas to reinforce the sequencing of installed components.

Two different residential course sections met asynchronously during the study period; each course had the same instructor and completed the same activities. Hands-on building activities took place each week during the final six weeks of the quarter, and utilized a kit of materials, delivered to students, and provided opportunities to utilize different building components, expanding on the material learned through assignments, reading, discussions, homework assignments, and video lectures.

Starting in week 4, students completed independent building activities to reinforce the knowledge learned that week, completing a built assembly and performing an inspection and reflection of the work completed. The six different building activities included (1) a foundation exercise building a formwork assembly with rebar, anchor bolts, and vapor barrier; (2) a framing exercise for stud layout and shear wall nailing; (3) a plumbing and electrical installation showing proper drainage, flow, and wiring methods; (4) exterior waterproofing utilizing building paper and housewrap; (5) the installation of batt insulation; and (6) drywall installation utilizing proper nail spacing. An introductory video was provided for each assignment, explaining how to use the tools or perform layout.

Students recorded their completed work utilizing an online video discussion board, highlighting the necessary code required items for construction as well as quality control items at the end of each exercise. After completing each assembly, students completed a video inspection, ensuring they met the installation requirements listed as part of the assignment. As part of the video, they also performed quality control, checking for square, level, proper spacing, etc. At the end of each video inspection, they included a reflection on lessons learned, challenges encountered, and something they were proud of as part of their built system. By default, all video inspections were kept private (shared with the instructor only), but students could opt to share with their classmates, providing additional comfort at each step of the building process. Each of the activities are further explained below. 


\section{Building Kit}

The instructor ordered all building materials and tools and assembled a complete building kit in a 12 " x 18 " x 8 " box. The kit included all materials needed to build each activity, as well as the necessary tools and personal protective equipment (PPE) to complete the work. All required holes were predrilled, so the only tools needed were a framing hammer, cable rippers, a tape measure, and a speed square. PPE included one pair of safety glasses, gloves, and disposable ear plugs. The cost of each kit was approximately $\$ 120$, and the department paid for all materials, tools, and PPE. The kits were then either mailed to the student's home, or picked up from the instructor for students in the local area.

\section{Foundation Exercise}

The first building activity was for a foundation system. Students assembled a sample formwork assembly utilizing $2 \times 4 \mathrm{~s}$, rebar, rebar chairs, an anchor bolt, an anchor bolt chair, vapor barrier, and duplex nails. The following instructions and requirements were included as part of the assignment:

1. The slab that you are creating will have a finished dimension of $201 / 2$ " $\times 201 / 2$ " square

2. The rebar will be placed in a grid pattern, with each bar being a minimum of $11 / 2$ " but no more than 3" away from the edge of the formwork. All rebar should be placed at the midpoint of the slab (or as close as you can come with the provided chairs).

3. The anchor bolt will go along the center of one wall, be secured in its chair, and have a minimum of 1 " of clearance to the bottom of the slab.

4. The vapor barrier is installed under the entire slab, directly under the concrete.

After completing the foundation assembly, students completed a video inspection, ensuring they met the installation requirements listed above, as well as making sure the forms were square, level, and the correct size.

\section{Framing Exercise}

The second activity was for a wall framing system. Students assembled a small wall section, completing layout and assembly of studs and a shear wall following a prescribed nailing schedule. The following instructions and requirements were included as part of the assignment:

1. The wall you are building is $231 / 2^{\prime \prime}$ long by $231 / 2$ " tall

2. You have one top plate and one bottom plate

3. The layout of the stud should follow a 16 " on center layout, as illustrated in the video

4. Your nailing schedule is as follows:

a. Top plate to studs (end nailing): Two (2) 16d nails at each stud

b. Bottom plate to studs (end nailing or toe nailing): Four (4) 8d nails at each stud

c. Shear wall nailing: $8 \mathrm{~d}$ nails, 5/12 (five-inch edge nailing; 12-inch field nailing)

\section{Electrical and Plumbing Exercise}

The third activity was for electrical and plumbing systems. Students installed plumbing drain lines with a sanitary wye and an electrical box and wiring. The following instructions and requirements were included as part of the assignment: 
1. The plumbing line will be installed vertically plumb, with the sanitary wye at approximately 6 inches above finish floor

2. The electrical box must be installed at 8 inches to the center of the box above finish floor, with a pigtail in the box, and approximately 12 " of wire

3. All electrical cabling must be secured/stapled per code

4. No bare copper from the wires (excluding the ground) should extend past the wire nut

5. Nail plates must be installed when a pipe or wire is less than $11 / 4$ " from the face of the stud

\section{Water Management Exercise}

The fourth activity was for exterior wall water management. Students installed housewrap and building paper using lath nails. The following instructions and requirements were included as part of the assignment:

1. The house wrap will go between your framing and your building paper to act as your drainage plane

2. The building paper must be lapped shingle style

3. The building paper must be overlapped correctly horizontally (verify horizontal overlap requirements with the text)

4. The building paper extends beyond the bottom of the bottom plate (verify requirements with the text and pretend the wall is built on a concrete slab)

\section{Insulation Exercise}

The fifth activity was for the installation of batt insulation in their wall assembly. Students installed batt insulation in their wall assembly. The following instructions and requirements were included as part of the assignment:

1. All $2 \times 4$ walls are $\mathrm{R}-13$ insulation

2. The vapor retarder is on the warm side of the wall (check your climate zone)

\section{Drywall Exercise}

The sixth and final activity was for the installation of drywall in their wall assembly. Students installed drywall on one section of their wall. The following instruction and requirements were included as part of the assignment:

1. Ensure your nailing meets code requirements

\section{Survey Results and Discussion}

Survey data was conducted over one quarter in two separate classes, with the same instructor providing course instruction. Of the 41 students enrolled in the course, 25 students completed both surveys, for a response rate of $60.9 \%$. The survey items are shown in Figures 1 and 2.

The first section of the survey asked students to rank their confidence in both their building abilities, using tools and performing quality control measures. In the pre-survey, the mean score was just above 
average, at a score of 3.4 out of five. In the post-survey, student scores increased by one point, to 4.4. Overall, students' confidence increased throughout the quarter for all areas. The area where students were most confident in both the pre- and post- survey was reading a tape measure, and this had the least amount of change between the pre-and post-survey results. The ability that had the greatest change was checking a system for plumb, with an increase of 1.56 points between surveys. Survey results for students' confidence in building abilities, using tools and performing quality control measures are shown in Figure 1.

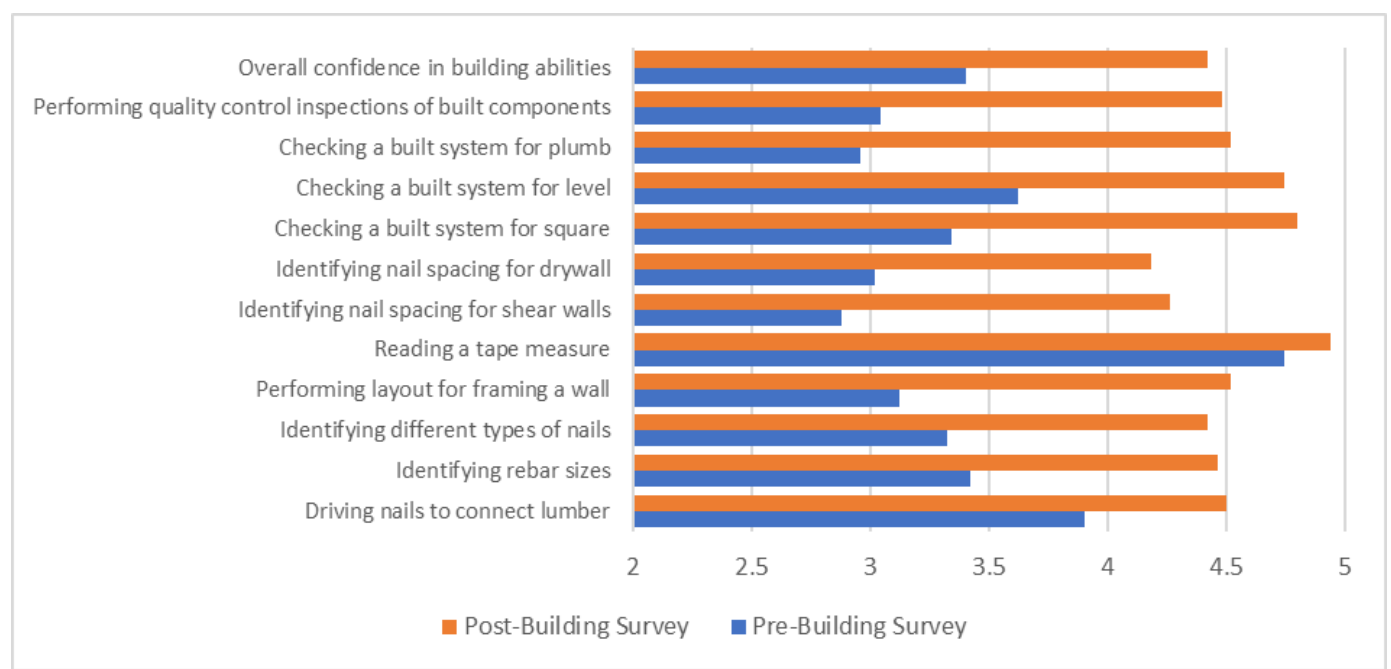

Figure 1. Students' confidence in building abilities, tool use, and quality control items.

The second section of the survey asked students to rank their confidence in identifying inspection items for each of the different building activities. Between the pre- and post- survey, student scores increased an average of 1.7 points, following a five-point Likert scale. Overall, students' confidence increased throughout the quarter for all areas. The area that had the greatest increase was lath, going from 2.3 during the pre-survey to 4.18 during the post survey, a difference of 1.88 points. At the end of the quarter, students identified framing as the area where they had greatest confidence in identifying inspection items, with lath having the lowest confidence levels.

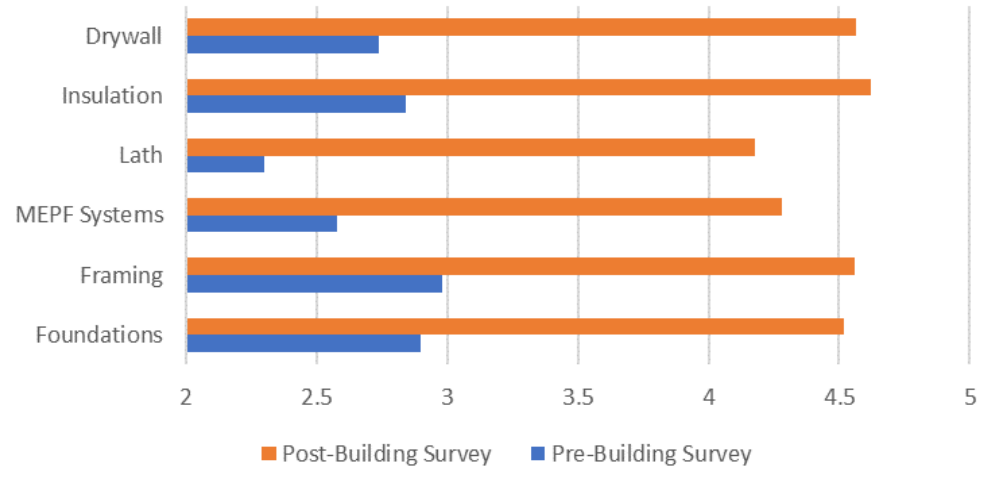

Figure 2. Students' confidence in identifying inspection items. 
In the post-survey, students were asked, on a scale of 1 to 10 (10 being the highest ranking) if they enjoyed the activity. The mean ranking was 9.32, with no student answering lower than an 8 .

Additionally, students were asked, on a scale of 1 to 10 , if they learned anything from the building activities. The mean ranking was a 9.4, with no student ranking lower than an 8 , and $64 \%$ of students proving a rank of 10 . Finally, students were asked if these activities should continue if classes remained virtual; an overwhelming $100 \%$ of the students agreed that these activities should continue.

Since students have different ways they prefer to learn, and may prefer different activities, students were also asked which of the six building activities they liked the most, and which they liked the least. Overall, the framing exercised was the most enjoyable activity, followed by the mechanical, plumbing and electrical systems. The least favorite activities were split almost evenly between all exercises, exclusive of the foundation activity. Students' favorite and least favorite activities are shown in Figures 3 and 4 respectively.

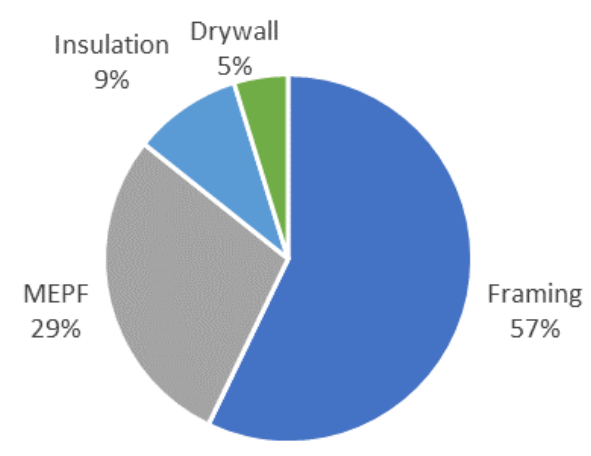

Figure 3. Favorite activity as identified by students.

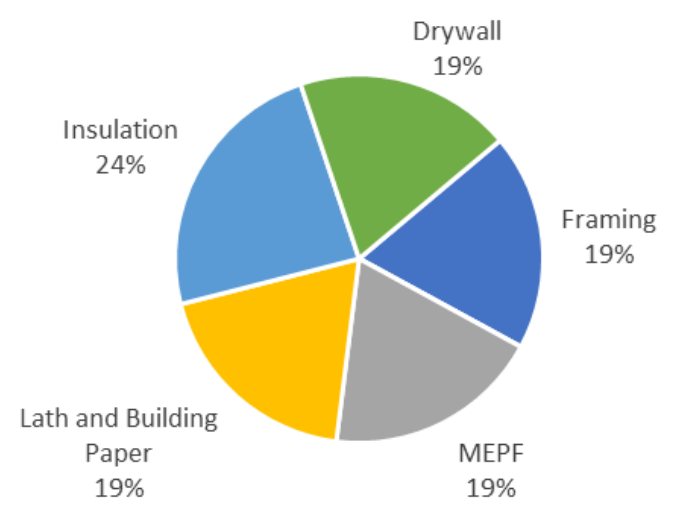

Figure 4. Least favorite activity as identified by students.

\section{Conclusion}

Previous studies indicated that students prefer hands-on experiential learning opportunities, and find them effective as an instructional delivery method (Kolegraff et al., 2019). Additionally, students perceived that these in-class hands-on building activities improved both their technical and soft skills 
(Kline et al., 2020). However, with the advent of the COVID-19 pandemic in 2020, construction management programs pivoted instruction to either fully asynchronous delivery or hybrid course formats. This study provided insight into how an experiential learning activity can be transitioned to a virtual course format for a residential construction management course.

This study provided insight into the types of learning activities that can be performed in a virtual environment, and the impact it had on student confidence as it pertains to building abilities and inspections. Overall, confidence was increased for both inspections as well as confidence in building abilities, use of tools, and quality control measures. Additionally, an overwhelming $100 \%$ stated that these activities should continue if classes were to remain virtual, and all students agreed that the activities were an enjoyable learning experience. Future research could analyze the specific features of each activity that students find most or least effective.

\section{References}

Benhart, B., Cabral, J., Hubbard, B., Metzinger, J., Morgan, P, \& Santon, S. (2017). Construction Management Curriculum Transformation through Project-Based Learning; Part 1 of a Progressive Case Study. Associated Schools of Construction International Proceedings of the $53^{\text {rd }}$ Annual Conference, 19-27.

Brinson, J. R. (2015). Learning outcome achievement in non-traditional (virtual and remote) versus traditional (hands-on) laboratories: A review of the empirical research. Computers and Education, 87, 218-237.

Chinowcky, P., Braown, H., Szajnman, A., \& Realph, A. (2006). Developing knowledge landscapes through project-based learning. Journal of Professional Issues in Engineering Issues and Practice, 132 (2), 118-124.

Kapici, H. O., Akcay, H., \& Jong, T. d. (2019). Using Hands-On and Virtual Laboratories Alone or Together-Which Works Better for Acquiring Knowledge and Skills? Journal of Science Education and Technology volume, 28, 231-250.

Kline, A., Kolegraff, S., \& Kelting, S. (2020). Students Perspectives of Experiential Learning in a Technical Education Program. IICE Hawaii 2020. Honolulu: IAFOR.

Kolegraff, S. A., Kline, A., \& Kelting, S. (2019). Hands-On Building as an Instructional Delivery Method in an Integrated Lab Curriculum. 55th ASC Annual International Conference Proceedings (pp. 33-40).

Montoya, M., Kelting, S., \& Hauck, A. (2009). Pilot Study of an Integrated Construction Management Curriculum. Associated Schools of Construction International Proceedings of the $45^{\text {th }}$ Annual Conference, 59-66.

Pratt, Daniel D., 1942. Five Perspectives on Teaching in Adult and Higher Education. Malabar, Fla.: Krieger Pub. Co., 1998. 
Smalley, A. (2020, December 17). Higher Education Responses to Coronavirus (COVID-19). Retrieved from: https://www.ncsl.org/research/education/higher-education-responses-tocoronavirus-covid-19.aspx. 